\title{
Favourable impact of low-calorie cranberry juice consumption on plasma HDL-cholesterol concentrations in men
}

\author{
Guillaume Ruel, Sonia Pomerleau, Patrick Couture, Simone Lemieux, Benoît Lamarche \\ and Charles Couillard* \\ Institute of Nutraceuticals and Functional Foods, Laval University, Québec G1K 7P4, Canada and Lipid Research Center \\ Laval University Medical Research Center, CHUL Pavilion, Quebec G1V 4G2, Canada
}

(Received 30 August 2005 - Revised 8 March 2006 - Accepted 20 March 2006)

\begin{abstract}
A low HDL-cholesterol concentration is an independent risk factor for CVD. Studies have suggested that flavonoid consumption may be cardioprotective, and a favourable impact on circulating HDL-cholesterol concentrations has been suggested to partially explain this association. The aim of the present study was to determine the effect of consuming increasing daily doses of low-calorie cranberry juice cocktail (CJC) on the plasma lipid profile of abdominally obese men. For that purpose, thirty men (mean age 51 (SD 10) years) consumed increasing doses of CJC during three successive periods of 4 weeks $(125 \mathrm{ml} / \mathrm{d}, 250 \mathrm{ml} / \mathrm{d}, 500 \mathrm{ml} / \mathrm{d})$. Before the study and after each phase, we measured changes in physical and metabolic variables. We noted a significant increase in plasma HDL-cholesterol concentration after the consumption of $250 \mathrm{ml} \mathrm{CJC} / \mathrm{d}$ $(+8.6 \pm 14.0 \%$ v. $0 \mathrm{ml} \mathrm{CJC} / \mathrm{d} ; P<0.01)$, an effect that plateaued during the last phase of the study $(500 \mathrm{ml} \mathrm{CJC} / \mathrm{d}:+8.1 \pm 10.0 \% v \cdot 0 \mathrm{ml}$ $\mathrm{CJC} / \mathrm{d} ; P<0.0001)$. Multivariate analyses revealed that changes in plasma apo A-I $\left(R^{2}=48 \%, P<0.0001\right)$ and triacylglycerol $\left(R^{2}=16 \%\right.$, $P<0.005)$ concentrations were the only variables significantly contributing to the variation in plasma HDL-cholesterol concentration noted in response to the intervention. No variation was observed in total as well as in LDL and VLDL cholesterol. The present results show that daily CJC consumption is associated with an increase in plasma HDL-cholesterol concentrations in abdominally obese men. We hypothesise that polyphenolic compounds from cranberries may be responsible for this effect, supporting the notion that the consumption of flavonoid-rich foods can be cardioprotective.
\end{abstract}

Cranberry: Flavonoids: Cardiovascular disease: HDL-cholesterol

A reduced HDL-cholesterol concentration is a well-established independent risk factor for CVD (Brewer, 2004), the leading cause of death in North America (American Heart Association, 2005). Although the role of HDL in reverse cholesterol transport is well documented, newly described characteristics of these particles, for example antioxidant activity, as well as antithrombogenic, fibrinolytic, antiadhesion and anti-inflammatory properties (Barter et al. 2003), are also believed to play a role in the cardioprotective potential of high circulating HDL-cholesterol concentrations.

In this sense, health professionals strongly advocate interventions aimed at increasing plasma HDL-cholesterol in the prevention of CVD, although such interventions remain limited. Among them, physical activity (Williams, 2004) and pharmacological treatment with fibrates (Birjmohun et al. 2005) and nicotinic acid (Squires et al. 1992) are known to raise plasma HDL-cholesterol concentration, this effect most probably resulting from the triacylglycerol-lowering effect associated with these treatments. Nutritional interventions aimed at raising HDL-cholesterol concentrations have not been so successful. Although $n-3$ PUFA intake has been shown to increase $\mathrm{HDL}_{3}$-cholesterol concentration slightly (Sacks et al. 1994; Tholstrup et al. 2004), the consumption of $n$-6 PUFA (Montoya et al. 2002; Sacks \& Katan, 2002) and carbohydrates (Sacks \& Katan, 2002) has been associated with reductions in plasma HDL-cholesterol concentration.

Observations have suggested that antioxidant (Duthie \& Bellizzi, 1999) supplementation may help to increase circulating HDL-cholesterol concentrations. Indeed, the consumption of flavonoid-rich foods such as grape juice (Albers et al. 2004), wine (Senault et al. 2000; Naissides et al. 2004), cacao (Mursu et al. 2004) and orange juice (Kurowska et al. 2000) have all been shown to increase plasma HDL-cholesterol concentrations. Cranberries (Vaccinium macrocarpon) are among the most important sources of polyphenolic compounds including flavonols, anthocyanins and proanthocyanidins (Sun et al. 2002; Zheng \& Wang, 2003), which confers to any cranberry-derived products, like juice, a potent antioxidant activity. The present study was therefore undertaken in order to investigate the effects of consuming increasing daily doses of low-calorie cranberry juice cocktail (CJC) on plasma lipoprotein concentrations in a group of abdominally obese men. 


\section{Materials and methods}

\section{Subjects}

Thirty-one healthy and sedentary men (mean age 51 (SD 10) years) were recruited through the media to participate in this 12-week intervention. To be part of the study, subjects had to have a waist circumference of $90 \mathrm{~cm}$ or more and a fasting plasma low LDL-cholesterol concentration of between 3.4 and $5.0 \mathrm{mmol} / \mathrm{l}$, and to be free from diabetes and CVD as well as renal, hepatic and endocrine disorders. Furthermore, they had to be non-smokers and not be using medications known to affect lipid or insulin metabolism. Subjects gave their written consent to participate in the study, which was approved by the Medical Ethics Committee of Laval University. One subject dropped out of the study for personal reasons not related to the intervention.

\section{Intervention}

Upon their entry into the study, subjects were instructed by a nutritionist to maintain their usual nutritional habits throughout the entire intervention. Participants were subjected to a 4-week run-in period that consisted of consuming $500 \mathrm{ml} / \mathrm{d}$ placebo juice (PJ). This juice has been developed by Ocean Spray Cranberries Inc. (Lakeville-Middleboro, MA, USA) and possesses organoleptic properties (taste, colour, texture) similar to those of regular CJC although it has no cranberries in its composition. A detailed description of the PJ and CJC is shown in Table 1. During the run-in period, participants were instructed to reduce their alcohol consumption to a maximum of $1 \mathrm{drink} / \mathrm{d}$ (equivalent to $15 \mathrm{~g}$ alcohol/d) and to refrain from consuming any vitamin, antioxidant or mineral supplements.

This run-in period was followed by three 4-week periods during which subjects successively consumed $125 \mathrm{ml}$ (phase 1), $250 \mathrm{ml}$ (phase 2) and $500 \mathrm{ml}$ (phase 3) CJC daily. These volumes were adjusted to $500 \mathrm{ml}$ liquid/d with the addition of 375,250 or $0 \mathrm{ml} \mathrm{PJ}$ for phases 1,2 and 3, respectively.

Table 1. Detailed description of the content of a portion $(125 \mathrm{ml})$ of placebo juice (PJ) and low-calorie cranberry juice cocktail (CJC)

(Values were means and standard deviations based on five determinations for each beverage)

\begin{tabular}{|c|c|c|c|c|}
\hline & \multicolumn{2}{|c|}{ PJ } & \multicolumn{2}{|c|}{ CJC } \\
\hline & Mean & SD & Mean & SD \\
\hline Energy (kJ) & $91 \cdot 3$ & & $91 \cdot 3$ & \\
\hline Carbohydrates (g) & 5.46 & 0.08 & 5.46 & 0.28 \\
\hline Ascorbic acid (mg) & 32 & & 32 & \\
\hline Total organic acids $(\mathrm{g})$ & 0.90 & 0.01 & 0.98 & 0.04 \\
\hline Total phenolics (mg) & 39 & 0.09 & 100 & $6 \cdot 50$ \\
\hline Total anthocyanins (mg) & n.d. & n.d. & $5 \cdot 2$ & 0.68 \\
\hline Cyanidin-3-galactoside & n.d. & n.d. & 0.91 & 0.33 \\
\hline Cyanidin-3-glucoside & n.d. & n.d. & 0.08 & 0.01 \\
\hline Cyanidin-3-arabinoside & n.d. & n.d. & $1 \cdot 3$ & 0.26 \\
\hline Peonidin-3-galactoside & n.d. & n.d. & 1.5 & 0.09 \\
\hline Peonidin-3-glucoside & n.d. & n.d. & 0.24 & 0.01 \\
\hline Peonidin-3-arabinoside & n.d. & n.d. & $1 \cdot 2$ & 0.09 \\
\hline Proanthocyanidins (mg) & n.d. & n.d. & 74 & $5 \cdot 21$ \\
\hline
\end{tabular}

Other ingredients included in PJ and CJC are filtered water, cranberry juice concentrate (CJC only), fructose, pectin, sodium citrate, ascorbic acid, sucralose, and acesulfame- $K$.

n.d., none determined.
This was achieved in order to minimise the impact of incorporating increasing quantities of liquid into the daily diet of subjects, and blind subjects from the level of treatment to which they had been assigned. All subjects had to complete the entire protocol in order to be considered for the statistical analyses.

In an effort to eliminate handling of the juice, PJ and CJC were packaged at Laval University in $125 \mathrm{ml}$ ready-to-drink TetraBrik boxes from Tetra-Pak (Richmond Hill, Ontario, Canada). Subjects had to drink four $125 \mathrm{ml}$ boxes/d, which were marked with a code indicating their content (PJ or CJC); this information was kept secret from the subjects and known only by the investigators. Subjects were also instructed to drink two boxes of juice (CJC or PJ depending on the phase) in the morning and two in the evening. Both the PJ and the CJC were kindly provided by Ocean Spray. The packaging sessions were monitored by Ocean Spray to ensure the adequate reconstitution and quality of both the PJ and CJC. All CJC used for the study was reconstituted from concentrate from the same processed batch of cranberries, in order to avoid any variations in the composition of the juice throughout the intervention. Furthermore, in an effort to keep the subjects' sugar consumption to a minimum and limit possible detrimental health effects, we provided subjects with the no-added-sugar version of Ocean Spray's low-calorie CJC.

\section{Composition of placebo juice and cranberry juice cocktail}

Characterisation of the composition of both PJ and CJC was performed by Ocean Spray. Briefly, carbohydrates were measured by refractometry using the Brix method. Quinic, malic and citric acids were measured by ion chromatography (Dionex Dx-500; Dionex Corporation, Sunnyvale, CA, USA) using a method developed by Ocean Spray. Proanthocyanidins were measured by HPLC-MS/MS using a previously described procedure (Gu et al. 2004). Finally, phenolic compounds and total/individual anthocyanins were assayed by HPLC (Spanos \& Wrolstad, 1990).

Both the PJ and CJC were artificially sweetened with sucralose (Splenda; McNeil Nutritionals LLC, Fort Washington, PA, USA) and acesulfame K. As indicated in Table 1, one box of $125 \mathrm{ml} \mathrm{CJC}$ or PJ contained $5.46 \mathrm{~g}$ carbohydrates and provided $91.3 \mathrm{~kJ}$ energy.

\section{Anthropometry}

Body weight and height as well as waist and hip circumferences were measured following standardised procedures (van der Kooy \& Seidell, 1993), and the BMI and waist-to-hip ratio were calculated.

\section{Plasma measurements}

At each visit to the investigation unit, blood samples were obtained from the subject's antecubital vein, in the morning after a $12 \mathrm{~h}$ fast. Upon collection, cholesterol and triacylglycerol (TG) concentrations were determined in plasma by enzymatic methods using a Technicon RA-1000 analyser (Bayer Corporation Inc, Tarrytown, NY, USA), as previously described (Moorjani et al. 1987). Plasma VLDL 
(density $<1.006 \mathrm{~g} / \mathrm{ml}$ ) were isolated by ultracentrifugation, and the HDL fraction was obtained after precipitation of LDL from the infranatant (density $>1.006 \mathrm{~g} / \mathrm{ml}$ ) with heparin and $\mathrm{MnCl}_{2}$ (Burstein et al. 1970). The cholesterol and TG contents of the infranatant fraction were measured before and after the precipitation step. apo A-I (plasma) and apo B (plasma, VLDL, LDL) concentrations were measured by nephelometry (Dade Behring, Mississauga, Ontario, Canada). The lyophilised serum standards for apo measurements were prepared at the Lipid Research Center of Laval University Medical Center and calibrated with reference standards obtained from the Centers for Disease Control (Atlanta, GA, USA).

\section{Antioxidant status and oxidative stress}

Total antioxidant capacity was measured in frozen plasma using a commercial kit (ImAnOx; ALPCO Diagnostics, Windham, NH, USA). Briefly, antioxidants present in plasma first react with $\mathrm{H}_{2} \mathrm{O}_{2}$. When the reaction is completed, the concentration of residual $\mathrm{H}_{2} \mathrm{O}_{2}$ is determined by spectrophotometry $(450 \mathrm{~nm})$. The antioxidant content of the sample is inversely proportional to the coloration of the mix.

Nitrite/nitrate (NOx) concentrations were determined as a marker of oxidative stress (Cayman Chemical Company, Ann Arbor, MI, USA). After conversion of nitrate to nitrite in the plasma sample, nitrites are converted into a deep purple azo compound using Griess reagent. When the reaction is completed, the concentration of the azo product is determined by spectrophotometry $(550 \mathrm{~nm})$ and is proportional to the nitrite/nitrate present in the sample.

\section{Nutritional habits assessment}

A ninety-one-item validated food-frequency questionnaire (Goulet et al. 2004) was administered by a nutritionist during each of the subjects' visit to the investigation unit. The food-frequency questionnaire was structured to reflect food habits of the Quebec population. Food items were listed in food groups: group 1, vegetables; group 2, fruits; group 3, legumes, nuts and seeds; group 4, cereals and grain products; group 5, milk and dairy products; group 6, meat/processed meat; group 7, poultry; group 8, fish; group 9, eggs; group 10, sweets; group 11, oils and fats; group 12, fast foods and drinks. During the interview, the nutritionist used food models for a better estimation of the real portions consumed by the subjects.

\section{Statistical analyses}

Data are presented as means and standard deviations unless stated otherwise. The MIXED model procedure was used to test for the main effect of dose. Tukey-Kramer adjusted $P$ values were used to determine statistical significance between doses when a significant effect was detected by the MIXED analysis. The significance of changes in physical and metabolic variables during the run-in period was tested with Student's paired $t$ tests. Associations between variables were quantified with Spearman correlation coefficients. We also performed regression analyses in order to sort out the independent contribution of different variables to the total change in plasma HDL-cholesterol concentrations in response to the intervention. All analyses were performed with the SAS statistical package (version 8.2; SAS Institute, Cary, NC, USA) and a $P$ value $\leq 0.05$ was considered significant.

\section{Results}

Changes in the subjects' physical characteristics in response to the intervention are shown in Table 2 . We noted small but significant decreases ( $v .0 \mathrm{ml} \mathrm{CJC} / \mathrm{d})$ in adiposity measures throughout the intervention, which reached values of -0.87 (SD 1.80$) \mathrm{kg}$ for body weight $(P<0.05),-0.28$ (SD 0.60$)$ $\mathrm{kg} / \mathrm{m}^{2}$ for BMI $(P<0.05)$ and $-1.87($ SD 1.81$) \mathrm{cm}$ for waist circumference $(P<0.0001)$ at the end of the study (Table 2$)$.

Table 2. Changes in physical and metabolic characteristics of the thirty men (Values were means and standard deviations)

\begin{tabular}{|c|c|c|c|c|c|c|c|c|c|}
\hline \multirow{2}{*}{ Variables } & \multicolumn{9}{|c|}{ Daily CJC consumption } \\
\hline & \multicolumn{2}{|c|}{$0 \mathrm{ml}$} & \multicolumn{2}{|c|}{$125 \mathrm{ml}$} & \multicolumn{2}{|c|}{$250 \mathrm{ml}$} & \multicolumn{2}{|c|}{$500 \mathrm{ml}$} & $P$ across doses \\
\hline Body weight (kg) & $84 \cdot 7$ & $12 \cdot 2$ & 84.4 & $12 \cdot 1$ & $84 \cdot 0^{\mathrm{a}}$ & $12 \cdot 2^{\mathrm{a}}$ & $83 \cdot 9^{a}$ & $12 \cdot 6^{a}$ & 0.0263 \\
\hline BMI $\left(\mathrm{kg} / \mathrm{m}^{2}\right)$ & $27 \cdot 8$ & $3 \cdot 3$ & $27 \cdot 7$ & $3 \cdot 3$ & $27 \cdot 6^{a}$ & $3 \cdot 3^{a}$ & $27 \cdot 5^{a}$ & $3 \cdot 4^{\mathrm{a}}$ & 0.0386 \\
\hline Waist circumference $(\mathrm{cm})$ & $97 \cdot 7$ & $7 \cdot 0$ & $96 \cdot 9^{a}$ & $7 \cdot 2^{a}$ & $96 \cdot 1^{\mathrm{a}, \mathrm{b}}$ & $7 \cdot 5^{\mathrm{a}, \mathrm{b}}$ & $95 \cdot 9^{a, b}$ & $7 \cdot 4^{\mathrm{a}, \mathrm{b}}$ & $<0.0001$ \\
\hline Waist-to-hip ratio & 0.95 & 0.05 & 0.95 & 0.04 & $0.94^{a}$ & $0.05^{a}$ & $0.94^{a}$ & $0.04^{a}$ & 0.0003 \\
\hline Total cholesterol (mmol/l) & $5 \cdot 84$ & $0 \cdot 76$ & 5.90 & 0.68 & $5 \cdot 86$ & 0.75 & $5 \cdot 82^{b}$ & $0 \cdot 82^{b}$ & 0.8476 \\
\hline Triacylglycerols $(\mathrm{mmol} / \mathrm{l})$ & 1.57 & 0.48 & 1.43 & 0.45 & 1.44 & 0.48 & 1.49 & 0.66 & 0.0553 \\
\hline LDL-cholesterol (mmol/l) & 4.03 & 0.64 & $4 \cdot 10$ & 0.60 & 4.04 & 0.67 & 3.97 & 0.73 & 0.5246 \\
\hline $\begin{array}{l}\text { Total:HDL-cholesterol } \\
\text { apo B (g/l) }\end{array}$ & 5.07 & $1 \cdot 13$ & 4.92 & 0.95 & $4 \cdot 71^{\mathrm{a}}$ & $0.96^{\mathrm{a}}$ & $4 \cdot 67^{a}$ & $0.94^{\mathrm{a}}$ & 0.0004 \\
\hline Plasma & $1 \cdot 16$ & $0 \cdot 20$ & $1 \cdot 19$ & 0.17 & $1 \cdot 16$ & 0.18 & $1 \cdot 18$ & 0.20 & 0.2362 \\
\hline VLDL & 0.13 & 0.03 & 0.12 & 0.03 & 0.12 & 0.03 & 0.13 & 0.03 & 0.1311 \\
\hline
\end{tabular}

CJC, cranberry juice cocktail.

${ }^{a}$ Different from $0 \mathrm{ml} \mathrm{CJC/d}$.

${ }^{\mathrm{b}}$ Different from $125 \mathrm{ml} \mathrm{CJC} / \mathrm{d}$. 
The intervention yielded a significant increase in plasma HDL-cholesterol concentration (Fig. 1). The difference reached statistical significance after subjects consumed $250 \mathrm{ml} \mathrm{CJC} / \mathrm{d}(+8.6$ (SD 14.0) \%; $P<0.05$ v. $0 \mathrm{ml} \mathrm{CJC/d}$ ), an effect that plateaued in the last phase of the study $(500 \mathrm{ml}$ $\mathrm{CJC} / \mathrm{d}$ ) but remained highly significant (+8.1 (SD 10.0)\%; $P<0.001$ v. $0 \mathrm{ml} \mathrm{CJC/d}$ ). Changes in plasma apo A-I concentration paralleled those of HDL-cholesterol, although the increase failed to reach statistical significance $(P$ across doses $=0 \cdot 0815$ ).

The effects of consuming increasing daily doses of CJC on other parameters of the plasma lipoprotein-lipid profile are presented in Table 2. We noted a reduction in plasma TG in response to the intervention that almost reached statistical significance $(P=0.0553)$. In addition, the ratio of total cholesterol to HDL-cholesterol significantly decreased during the study $(P<0.0005)$, an effect attributed mostly to the concomitant increase in HDL-cholesterol. However, we found no effect of the intervention on plasma total and LDL-cholesterol concentrations or on circulating apoB levels (plasma, VLDL or LDL).
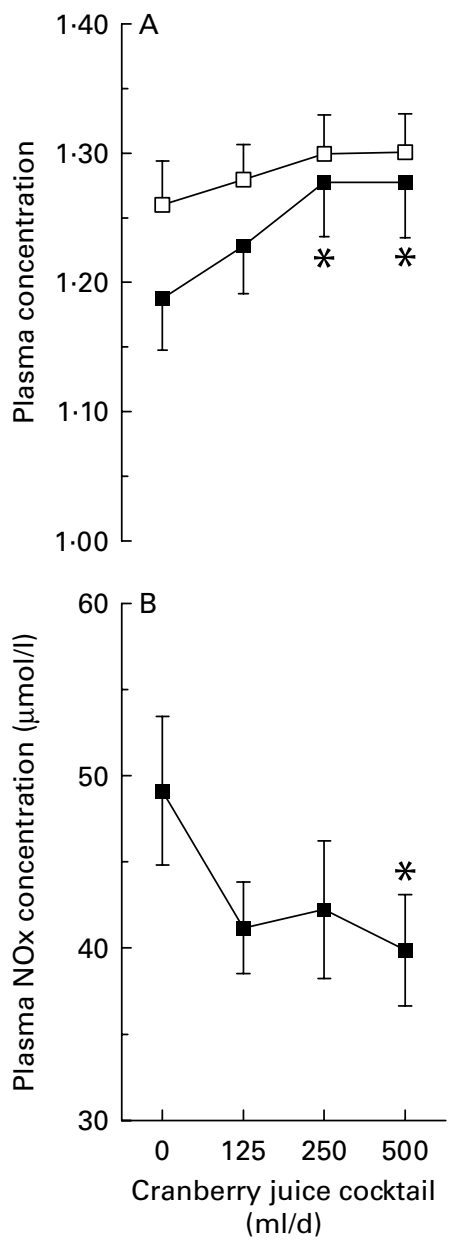

Fig. 1. Changes in (A) plasma HDL-cholesterol ( $\mathrm{mmol} / \mathrm{l} ; \mathbf{\square} ; P$ value across doses $=0.0010$ ), and apolipoprotein (apo) A-I ( $\square ; P=0.0815)$, as well as in (B) plasma nitrite/nitrate (NOx; $g / l ; P=0.0413$ ) concentrations during the course of the intervention. Values are means and their standard errors. ${ }^{*}$ Significantly different $v$. $0 \mathrm{ml}$ cranberry juice cocktail/d values; $P<0.05$.
Plasma total antioxidant capacity changed significantly during the course of the intervention $(P=0.0058)$. After a nearly significant increase in the first phase of the intervention (125 $\mathrm{ml} v .0 \mathrm{ml} \mathrm{CJC/d} P=0.0619)$, plasma total antioxidant capacity decreased at the $250 \mathrm{ml}(-3.6($ SD 6.8) $\%, P<0.05$ v. $125 \mathrm{ml} \mathrm{CJC/d}$ ) and $500 \mathrm{ml}(-6.2(\mathrm{SD} 10.4) \% ; P<0.05 v$. $125 \mathrm{ml} \mathrm{CJC/d}$ ) doses. We also noted a significant reduction in oxidative stress, as shown by the decrease in plasma nitrite/nitrate concentration following the last phase of the intervention ( -7.4 (SD 43) \%; $P<0.05$ v. $0 \mathrm{ml} \mathrm{CJC/d}$; Fig. 1). In addition, we found a significant association between the decrease in plasma nitrite/nitrate and the increase in apo A-I concentrations ( $-0.45 ; P<0.05$; Fig. 2).

The composition of the subjects' diet in the course of the intervention is given in Table 3 . We found no significant change in energy or macronutrient intake over the entire investigation. During the run-in period prior to the intervention, however, subjects spontaneously reduced their total energy intake $(-1984(\mathrm{SD} 2476) \mathrm{kJ} / \mathrm{d} ; P<0.0001)$ and changed the proportion of energy coming from lipids $(-2 \cdot 8$ (SD 5.37) $\% ; \quad P<0.01), \quad$ carbohydrates $(+4.1 \quad$ (SD 5.4)\%; $P<0.0005)$ and alcohol $(-1.1$ (SD $1.8 \%) ; P<0.005)$. No other changes in the subjects' diet prior to the intervention were noted.

In an attempt to explain the HDL-cholesterol increase in response to the intervention, we examined the associations between changes in metabolic and physical characteristics and plasma HDL-cholesterol concentration over the course of the study (Table 4). We found significant associations between the increase in plasma HDL-cholesterol and reductions in body weight and BMI as well as in plasma TG. The significant decrease in waist circumference noted during the intervention was not, however, correlated with the change in circulating HDL-cholesterol concentration.

Finally, in order to assess the potential independent contributions of changes in physical and metabolic variables during

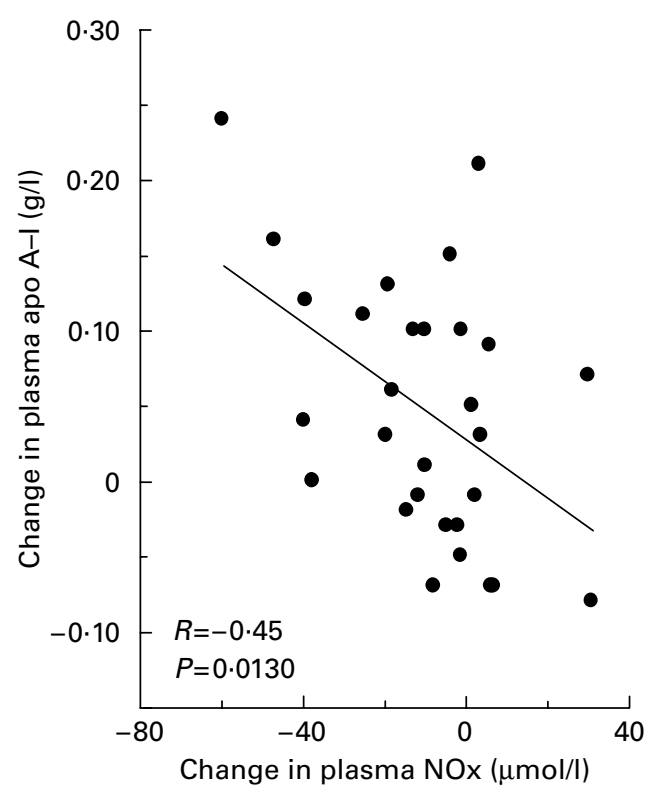

Fig. 2. Correlation between changes in plasma nitrite/nitrate (NOx) and apo A-I concentrations over the entire intervention in the thirty men. 
Table 3. Changes in daily macronutrient and micronutrient intake during the intervention

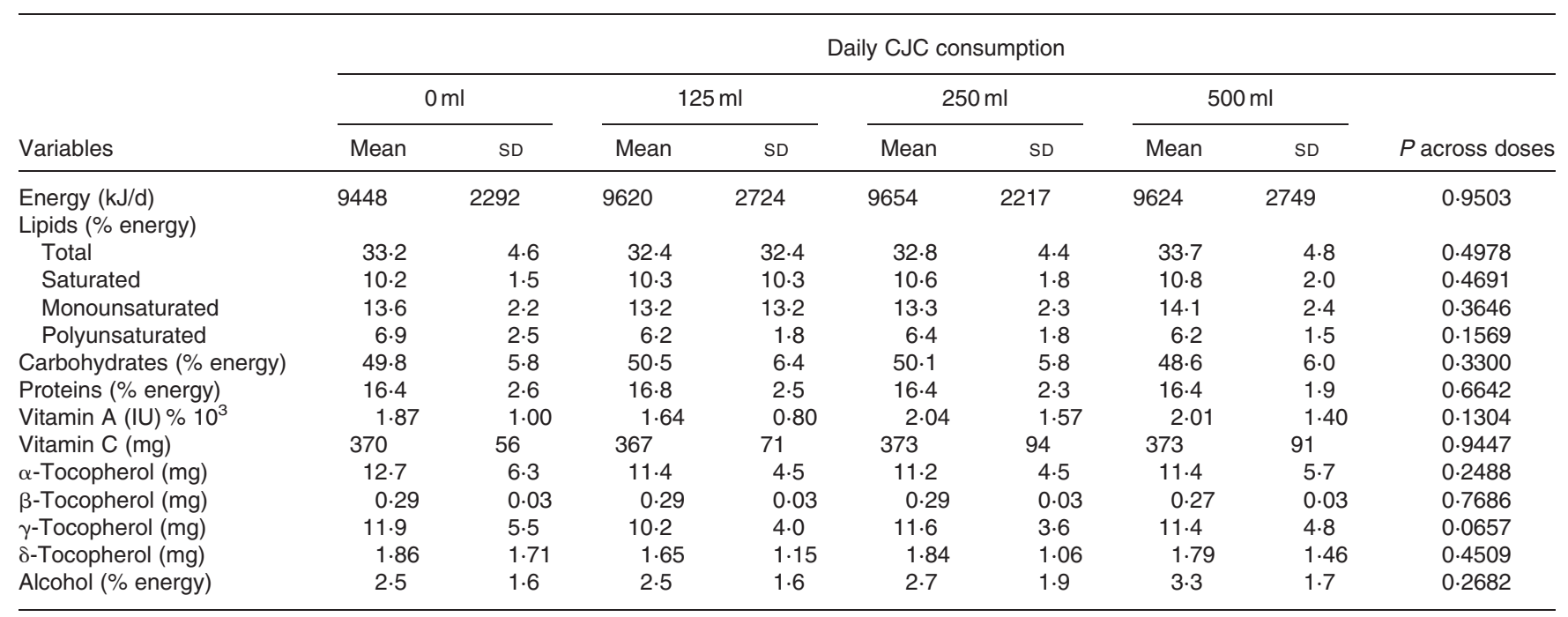

CJC, cranberry juice cocktail.

the intervention to the variation in plasma HDL-cholesterol concentration, we conducted regression analyses (Table 5) and found that changes in plasma apo A-I (48\%) and TG $(16 \%)$ concentrations were the only significant contributors to the changes in plasma HDL-cholesterol concentration.

\section{Discussion}

The present study shows that daily low-calorie CJC consumption is associated with an $8 \%$ increase in plasma HDL-cholesterol concentration in abdominally obese men. Interestingly, the extent of this increase is near the one usually obtained (approximately $10 \%$ ) with fibrate therapy, as recently reviewed (Birjmohun et al. 2005). To our knowledge, the present study is the first clinical intervention to report such an effect of CJC in human subjects and, in this sense, our observations are supportive of the cardioprotective potential of cranberries that has been recently suggested (Reed, 2002).

Table 4. Correlations between changes in plasma HDL-cholesterol concentrations and physical as well as metabolic variables over the entire intervention ( $0 \mathrm{ml}$ v. $500 \mathrm{ml}$ cranberry juice cocktail/d)

\begin{tabular}{lrc}
\hline & \multicolumn{2}{c}{ Change in HDL-cholesterol } \\
\cline { 2 - 3 } Changes in & $r$ & $P$ \\
\hline Body weight & -0.37 & 0.0437 \\
BMI & -0.42 & 0.0212 \\
Waist circumference & -0.26 & 0.1595 \\
Hip circumference & -0.26 & 0.1714 \\
Waist-to-hip ratio & -0.05 & 0.7869 \\
Total cholesterol & 0.01 & 0.9665 \\
Triglycerides & -0.39 & 0.0337 \\
LDL-cholesterol & 0.10 & 0.5900 \\
apo A-I & 0.62 & 0.0003 \\
apo B & -0.16 & 0.4039 \\
Antioxidant capacity & 0.13 & 0.4836 \\
Nitrite/nitrate & -0.02 & 0.9358 \\
\hline
\end{tabular}

Our results are also concordant with studies showing that the consumption of other flavonoid-rich beverages, such as wine (Araya et al. 2001; Chung et al. 2004) as well as grape (Albers et al. 2004) and orange (Kurowska et al. 2000) juice, has increasing effects on circulating HDL-cholesterol concentration. This benefit was previously suggested to be attributable to antioxidants present in these products, a hypothesis that could also apply to cranberries as they are an important source of polyphenolic compounds with potent antioxidant activity (Hakkinen et al. 1999; Sun et al. 2002).

The proposed HDL-cholesterol-raising effect of cranberry juice supplementation was not, however, noted in a 12-week intervention among type 2 diabetes patients (Chambers \& Camire, 2003). In their study, Chambers \& Camire used cranberry juice concentrate powder capsules equivalent to $240 \mathrm{ml}$ $\mathrm{CJC} / \mathrm{d}$, and the possibility that the heat-processing necessary to convert the cranberry concentrate to a powder had altered its bioactivity was raised by the authors as a possible explanation for their results. Furthermore, two previous 2-week studies by our group (Ruel et al. 2005a) and Duthie et al. (2005a) found no effect of CJC on HDL-cholesterol. Differences in the populations under investigation as well as the study aims and designs may partly explain discrepancies between this study and the present one. For example, the duration of the intervention needs to be further examined in terms of the potential cardiovascular health benefits associated with CJC consumption.

The increase in HDL-cholesterol concentration in response to our intervention could be explained by numerous physiological mechanisms, although most of them have still to be investigated and confirmed. There is a well-known inverse relationship between plasma TG and HDL-cholesterol concentrations (Austin, 1991); this is the result of the action of the cholesterol ester transfer protein, which leads to the TG enrichment and cholesterol impoverishment of HDL particles (Tall, 1986). In the present study, we noted a small decrease in plasma TG concentration following the intervention that almost reached statistical significance. As TG and HDL 
Table 5. Multivariate regression analyses showing the independent contributions of changes in adiposity and plasma lipids to the variance of the change in plasma HDL-cholesterol concentrations

\begin{tabular}{lcccc}
\hline Dependent variable & Independent variable & Partial $\left(R^{2} \% 100\right)$ & $P$ & Total $\left(R^{2} \% 100\right)$ \\
\hline$\Delta$ HDL-cholesterol & $\Delta$ apo A-I & 47.7 & 0.0001 & 63.7 \\
& $\Delta$ Triacylglycerols & 16.0 & 0.0019 & \\
\hline
\end{tabular}

The statistical model included changes in plasma apo A-I and triglyceride concentrations as well as those of BMI and body weight noted during the entire intervention.

metabolism are closely associated, even a small change in plasma TG could have had an impact on circulating HDL cholesterol concentrations. However, the decrease in TG noted in our study was not a major determinant of the increase in HDL-cholesterol concentration, an assumption that is supported by our multivariate analyses showing that the variation in plasma TG accounted for only $16 \%$ of the variation in plasma HDL-cholesterol level.

On the other hand, we found a strong relationship between the elevation of plasma HDL-cholesterol and apo A-I, the change in plasma apo A-I concentration explaining almost half (approximately $48 \%$ ) of the variation in HDL-cholesterol concentration during the course of the intervention. This relationship could either reflect a decrease in the clearance of HDL particles and/ or an increase in the synthesis of apo A-I during the course of the intervention. Although studies are needed to further investigate these mechanisms, the latter explanation could be the result of an increased production of apo A-I, an effect that could be similar to the one reported following the consumption of red wine (Senault et al. 2000), a food rich in polyphenolic compounds, as are cranberries.

Furthermore, there is in vitro evidence showing cross-linking between oxidised apo A-I molecules, a process that impairs their role in reverse cholesterol transport (Francis, 2000). Although oxidised apo A-I was not measured in the present study, a possible reduction in apo A-I oxidation following CJC consumption could also have contributed to the increase in plasma HDL-cholesterol concentration. In support of this hypothesis, changes in oxidative stress during the course of the intervention, assessed through plasma nitrite/ nitrate levels, were negatively associated with the changes in plasma apo A-I concentration.

It has also been shown that quercetin, highly present in cranberries, can increase the expression of the HDL-associated enzyme paraoxonase-1 (Gouedard et al. 2004), conferring a greater antioxidant activity on HDL particles. Paraoxonase-1 has also been recently shown to be a stimulant of macrophage cholesterol efflux (Rosenblat et al. 2005), leading to an increase in circulating HDL cholesterol level. Unfortunately, paraoxonase- 1 activity in HDL was not measured in the present study.

Furthermore, a possible indirect effect of cranberry antioxidants on the activity of the adenosine triphosphate-binding cassette transporter A1, a protein closely implicated in the release of cholesterol from macrophages to HDL (Singaraja et al. 2002), cannot be excluded either as cranberry antioxidants have been shown to increase levels of salicylates in the urine and plasma (Duthie et al. 2005b), and these compounds can increase adenosine triphosphate-binding cassette transporter A1 and scavenger receptor class B type 1 expression in macrophages (Vinals et al. 2005). Further studies will need to be conducted in order to validate this assumption.

Surprisingly, the consumption of CJC appeared to have limited impact on antioxidant defences of our subjects. Indeed, after a nearly significant increase after consuming $125 \mathrm{ml}$ $\mathrm{CJC} / \mathrm{d}$ for 4 weeks, total plasma antioxidant capacity gradually decreased to reached pre-intervention values when the subjects increased their CJC consumption to 250 and $500 \mathrm{ml} / \mathrm{d}$, which is in accordance with a previous study (Duthie et al. 2005b). Our observations are, however, in contrast with another study we recently conducted in which a 14 d CJC supplementation led to a significant increase in plasma total antioxidant capacity (Ruel et al. 2005b). A difference in the duration of the treatment or in the methodology used to assess plasma antioxidant capacity could explain the discrepancy between the two studies. On the other hand, it has been reported that there is a rapid degradation of dietary and possibly active flavonoids in plasma (Zhang \& Zuo, 2004). Because total plasma antioxidant capacity in the present study was measured in the fasting state, it may not be an accurate measure of levels of active antioxidant.

The absence of a control group (placebo) may represent a limitation of our study, although designs similar to ours have been used previously in studies looking at the effect of fruits and beverages on variables of the CVD risk profile (Stein et al. 1999; Keevil et al. 2000; Kurowska et al. 2000; Freedman et al. 2001; O'Byrne et al. 2002; Ruel et al. 2005b). Placebo-controlled studies will have to be conducted in order to support the observations reported in the present paper.

One important drawback of our study is that we were not able to clearly assess whether the favourable changes in plasma HDL-cholesterol concentration that we noted were the result of increasing doses of CJC or of increasing duration of the intervention. To that end, we feel that the duration of treatment may be more important than the daily dose of CJC as a previous $14 \mathrm{~d}$ trial conducted by our group, during which twenty-one healthy men were asked to drink $7 \mathrm{ml} / \mathrm{kg}$ body weight per d CJC (approximately $600 \mathrm{ml} / \mathrm{d}$ ), yielded a significant reduction in plasma oxidised LDL concentration but had no effect on other parameters of the lipid profile, including HDL-cholesterol (Ruel et al. 2005a). In addition, in a recent placebo-controlled, double-blind study, the consumption of $750 \mathrm{ml} / \mathrm{d}$ cranberry juice for 2 weeks had no effect on plasma lipids in a group of twenty healthy women (Duthie et al. 2005a). These recent observations tend to support the favourable impact of the duration of intervention in terms of the favourable effect of consuming CJC on circulating HDL-cholesterol level.

In summary, we report an HDL-cholesterol-increasing effect of low-calorie CJC consumption, which reinforces the notion that health benefits can be derived from consuming 
antioxidant-rich (e.g. flavonoid) foods. It is our understanding that antioxidants present in CJC are most likely implicated in this favourable change in plasma HDL-cholesterol concentration, although the exact physiological mechanisms through which such an effect occurs remain to be identified.

\section{Acknowledgements}

This study was supported by an unrestricted grant from the Canadian Cranberry Growers Coalition. C. C., S. L. and P. C. are research scholars from the Fonds de la recherche en santé du Québec (FRSQ). C. C. is also supported by the Chair in Nutrition, Lipidology and Cardiovascular Disease funded by Pfizer Canada and Provigo. B. L. holds a Canada Research Chair in Nutrition, Functional Foods and Cardiovascular Disease.

The authors would like to thank Marge Leahy $\mathrm{PhD}$ and Robin Roderick MSc from Ocean Spray Cranberries Inc. for kindly assessing the composition of CJC and placebo, as well as supervising the packaging sessions at Laval University. We also acknowledge the contributions of Danielle Aubin (RN), as well as Mélanie Martineau, Jocelyne Giasson, Raoul Géra, Pascal Cliche and Bernard Béliveau (Food Transformation Laboratory, Laval University). Finally, we would like to thank the subjects who participated in this study, without whom no clinical research would be possible.

\section{References}

American Heart Association (2005) Heart Disease and Stroke Statistic - 2005 Update. Dallas, TX: American Heart Association.

Albers AR, Varghese S, Vitseva O, Vita JA \& Freedman JE (2004) The antiinflammatory effects of purple grape juice consumption in subjects with stable coronary artery disease. Arterioscler Thromb Vasc Biol 24, e179-e180.

Araya J, Rodrigo R, Orellana M \& Rivera G (2001) Red wine raises plasma HDL and preserves long-chain polyunsaturated fatty acids in rat kidney and erythrocytes. Br J Nutr 86, 189-195.

Austin MA (1991) Plasma triglyceride and coronary heart disease. Arterioscler Thromb 11, 2-14.

Barter P, Kastelein J, Nunn A \& Hobbs R (2003) High density lipoproteins (HDLs) and atherosclerosis: the unanswered questions. Atherosclerosis 168, 195-211.

Birjmohun RS, Hutten BA, Kastelein JJ \& Stroes ES (2005) Efficacy and safety of high-density lipoprotein cholesterol-increasing compounds: a meta-analysis of randomized controlled trials. $\mathrm{J} \mathrm{Am}$ Coll Cardiol 45, 185-197.

Brewer HB Jr (2004) Focus on high-density lipoproteins in reducing cardiovascular risk. Am Heart J 148, S14-S18.

Burstein M , Scholnick HR, Morfin R. Rapid method for the isolation of lipoproteins from human serum by precipitation with polyanions (1970) J Lipid Res 11, 583-595.

Chambers BK \& Camire ME (2003) Can cranberry supplementation benefit adults with type 2 diabetes? Diabetes Care 26, 2695-2696.

Chung HS, Hong SH, Do KR, Rhee HK, Jung SK, Hwang WJ \& Kim HM (2004) MooPoong (Gye Young Jeong) increases HDL-cholesterol but decreases LDL cholesterol and body-weight. Immипоpharmacol Immunotoxicol 26, 225-232.

Duthie GG \& Bellizzi MC (1999) Effects of antioxidants on vascular health. Br Med Bull 55, 568-577.

Duthie SJ, Jenkinson AM, Crozier A, Mullen W, Pirie L, Kyle J, Yap LS, Christen P \& Duthie GG (2005a) The effects of cranberry juice consumption on antioxidant status and biomarkers relating to heart disease and cancer in healthy human volunteers. Eur J Nutr 45, $113-122$.

Duthie GG, Kyle JA, Jenkinson AM, Duthie SJ, Baxter GJ \& Paterson JR (2005b) Increased salicylate concentrations in urine of human volunteers after consumption of cranberry juice. J Agric Food Chem 53, 2897-2900.

Francis GA (2000) High density lipoprotein oxidation: in vitro susceptibility and potential in vivo consequences. Biochim Biophys Acta 1483, 217-235.

Freedman JE, Parker C 3rd, Li L, Perlman JA, Frei B, Ivanov V, Deak LR, Iafrati MD \& Folts JD (2001) Select flavonoids and whole juice from purple grapes inhibit platelet function and enhance nitric oxide release. Circulation 103, 2792-2798.

Gouedard C, Barouki R \& Morel Y (2004) Dietary polyphenols increase paraoxonase 1 gene expression by an aryl hydrocarbon receptor-dependent mechanism. Mol Cell Biol 24, 5209-5222.

Goulet J, Nadeau G, Lapointe A, Lamarche B \& Lemieux S (2004) Validity and reproducibility of an interviewer-administered food frequency questionnaire for healthy French-Canadian men and women. Nutr J 3, 13.

Gu L, Kelm MA, Hammerstone JF, Beecher G, Holden J, Haytowitz D, Gebhardt S \& Prior RL (2004) Concentrations of proanthocyanidins in common foods and estimations of normal consumption. J Nutr 134, 613-617.

Hakkinen SH, Karenlampi SO, Heinonen IM, Mykkanen HM \& Torronen AR (1999) Content of the flavonols quercetin, myricetin, and kaempferol in 25 edible berries. J Agric Food Chem 47, 2274-2279.

Keevil JG, Osman HE, Reed JD \& Folts JD (2000) Grape juice, but not orange juice or grapefruit juice, inhibits human platelet aggregation. J Nutr 130, 53-56.

Kurowska EM, Spence JD, Jordan J, Wetmore S, Freeman DJ, Piche LA \& Serratore P (2000) HDL-cholesterol-raising effect of orange juice in subjects with hypercholesterolemia. Am J Clin Nutr 72, $1095-1100$.

Montoya MT, Porres A, Serrano S, Fruchart JC, Mata P, Gerique JA \& Castro GR (2002) Fatty acid saturation of the diet and plasma lipid concentrations, lipoprotein particle concentrations, and cholesterol efflux capacity. Am J Clin Nutr 75, 484-491.

Moorjani S, Dupont A, Labrie F, Lupien PJ, Brun D, Gagne C, Giguere M \& Belanger A (1987) Increase in plasma high-density lipoprotein concentration following complete androgen blockage in men with prostatic carcinoma. Metabolism 36, 244-250.

Mursu J, Voutilainen S, Nurmi T, Rissanen TH, Virtanen JK, Kaikkonen J, Nyyssonen K \& Salonen JT (2004) Dark chocolate consumption increases HDL cholesterol concentration and chocolate fatty acids may inhibit lipid peroxidation in healthy humans. Free Radic Biol Med 37, 1351-1359.

Naissides M, Pal S, James AP \& Mamo JC (2004) The effect of red wine polyphenols on cardiovascular disease risk in postmenopausal women. Asia Pac J Clin Nutr 13, S71.

O'Byrne DJ, Devaraj S, Grundy SM \& Jialal I (2002) Comparison of the antioxidant effects of Concord grape juice flavonoids alphatocopherol on markers of oxidative stress in healthy adults. Am J Clin Nutr 76, 1367-1374.

Reed J (2002) Cranberry flavonoids, atherosclerosis and cardiovascular health. Crit Rev Food Sci Nutr 42, 301-316.

Rosenblat M, Karry R, \& Aviram M (2005) Paraoxonase 1 (PON1) is a more potent antioxidant and stimulant of macrophage cholesterol efflux, when present in HDL than in lipoprotein-deficient serum: relevance to diabetes. Atherosclerosis (Epublication ahead of print version).

Ruel G, Pomerleau S, Couture P, Lamarche B \& Couillard C (2005a) Changes in plasma antioxidant capacity and oxidized low-density lipoprotein levels in men following short-term cranberry juice consumption. Metabolism 54, 856-861. 
Ruel G, Pomerleau S, Couture P, Lamarche B \& Couillard C (2005b) Changes in plasma antioxidant capacity and oxidized low-density lipoprotein levels in men after short-term cranberry juice consumption. Metabolism 54, 856-861.

Sacks FM, Hebert P, Appel LJ, et al. (1994) Short report: the effect of fish oil on blood pressure and high-density lipoprotein-cholesterol levels in phase I of the Trials of Hypertension Prevention. J Hypertens 12, 209-213.

Sacks FM \& Katan M (2002) Randomized clinical trials on the effects of dietary fat and carbohydrate on plasma lipoproteins and cardiovascular disease. Am J Med 113, Suppl. 9B, 13S-24S.

Senault C, Betoulle D, Luc G, Hauw P, Rigaud D \& Fumeron F (2000) Beneficial effects of a moderate consumption of red wine on cellular cholesterol efflux in young men. Nutr Metab Cardiovasc Dis 10, 63-69.

Singaraja RR, Fievet C, Castro G, et al. (2002) Increased ABCA1 activity protects against atherosclerosis. J Clin Invest 110, 35-42.

Spanos GA \& Wrolstad RE (1990) Influence of processing and storage on the phenolic composition of Thompson seedless grape juice. J Agric Food Chem 38, 1565-1571.

Squires RW, Allison TG, Gau GT, Miller TD \& Kottke BA (1992) Low-dose, time-release nicotinic acid: effects in selected patients with low concentrations of high-density lipoprotein cholesterol. Mayo Clin Proc 67, 855-860.

Stein JH, Keevil JG, Wiebe DA, Aeschlimann S \& Folts JD (1999) Purple grape juice improves endothelial function and reduces the susceptibility of LDL cholesterol to oxidation in patients with coronary artery disease. Circulation 100, 1050-1055.

Sun J, Chu YF, Wu X \& Liu RH (2002) Antioxidant and antiproliferative activities of common fruits. J Agric Food Chem 50, 7449-7454.

Tall AR (1986) Plasma lipid transfer proteins. J Lipid Res 27, $361-367$.

Tholstrup T, Hellgren LI, Petersen M, Basu S, Straarup EM, Schnohr P \& Sandstrom B (2004) A solid dietary fat containing fish oil redistributes lipoprotein subclasses without increasing oxidative stress in men. J Nutr 134, 1051-1057.

van der Kooy K \& Seidell JC (1993) Techniques for the measurement of visceral fat: a practical guide. Int J Obes Relat Metab Disord 17, $187-196$.

Vinals M, Bermudez I, Llaverias G, Alegret M, Sanchez RM, Vazquez-Carrera M \& Laguna JC (2005) Aspirin increases CD36, SR-BI, and ABCA1 expression in human THP-1 macrophages. Cardiovasc Res 66, 141-149.

Williams PT (2004) Vigorous exercise and the population distribution of body weight. Int J Obes Relat Metab Disord 28, 120-128.

Zhang K \& Zuo Y (2004) GC-MS determination of flavonoids and phenolic and benzoic acids in human plasma after consumption of cranberry juice. J Agric Food Chem 52, 222-227.

Zheng W \& Wang SY (2003) Oxygen radical absorbing capacity of phenolics in blueberries, cranberries, chokeberries, and lingonberries. J Agric Food Chem 51, 502-509. 